\author{
EVS-25 \\ Shenzhen, China, Nov. 5-9, 2010
}

\title{
Design and Simulation for Fuel Cell Cathode Air Filter
}

\author{
Hong $\mathrm{Lv}^{1,2}$, Pai Liu ${ }^{1,2}$,Shujuan Cai ${ }^{1,2}$, Daijun Yang ${ }^{1,2}$, Jianxin $\mathrm{Ma}^{1,2}$ \\ 1.School of Automotive Studies, Tongji University, Shanghai, 201804, P.R. China \\ 2.Clean Energy Automotive Engineering Center, Tongji University, Shanghai, 201804, P.R. China, \\ (corresponding author: Jianxin Ma, jxma@tongji.edu.cn)
}

\begin{abstract}
Proton exchange membrane (PEM) fuel cells experience performance degradation, such as reduction in efficiency and life, as a result of poisoning of platinum catalysts by airborne contaminants. The best method for addressing fuel cell air contamination is by the inclusion of adsorptive filtration with a cathode air filter. In this paper, simulation for chemical adsorption behavior of air filter has been studied, which is based on Fluent. The adsorption of $\mathrm{SO}_{2}$ was simulated in the air filter, which structure was designed and optimized for a $5 \mathrm{~kW}$ fuel cell stack system. Not only the distribution of $\mathrm{SO}_{2}$ capacity with time in filter could be shown, but also the durability of filter can be evaluated. Furthermore, the velocity of flow and pressure drop of filter also were simulated. The simulation study for chemical adsorption and hydrodynamics in fuel cell cathode air filter help to optimize air filter to be durable and effective.
\end{abstract}

Keywords:Simulation, Chemical Adsorptive, Air Filter, PEM Fuel Cell

\section{Introduction}

Proton exchange membrane fuel cells (PEMFCs) are being developed as an alternative to the internal combustion engine (ICE) for automotive propulsion in order to reduce fossil fuel consumption. However, air in these operating environments may contain contaminants that are damaging to fuel cell performance, especially once emitted from ICE vehicles [1]. There have been many studies regarding the impact of various air contaminants[1-5]. For example, $1 \mathrm{ppm}$ of $\mathrm{NO}_{2}$ could reduce fuel cell performance by $10 \%$ while the same concentration of $\mathrm{SO}_{2}$ caused a $35 \%$ loss of cell voltage within $100 \mathrm{~h} \mathrm{[2]}$. Hundred and forty parts per million of NOx $\left(\mathrm{NO}: \mathrm{NO}_{2}=9: 1\right)$ could cause a $30 \%$ reduction in cell voltage within $5 \mathrm{~min}$ [1]. However, the effects of $\mathrm{CO}$ and hydrocarbon (i.e. benzene and propane) were less severe than those of $\mathrm{NO}_{\mathrm{x}}$ and $\mathrm{SO}_{2}$ [4,5]. Furthermore, the performance of fuel cells could not be fully recovered after poisoning by $\mathrm{NO}_{\mathrm{x}}$ or $\mathrm{SO}_{2}$. Therefore, it is a challenge to prevent the cathode from the contamination of $\mathrm{NO}_{\mathrm{x}}$ and $\mathrm{SO}_{2}$ in air when operating fuel cell vehicles in real environment.
Two methods for dealing with contaminated air effects on fuel cell cathodes are to increase catalyst durability and/or to filter contaminants from the air. Because of the wide variety of contaminants, increasing membrane resilience by modifying the catalyst or increasing the catalyst amount is a difficult and possibly expensive alternative. Therefore, the most effective and flexible method for operating fuel cells in contaminated environments is adsorptive filtration of contaminants from the ambient air stream[5].

The designing parameters of an adsorptive filter, including saturation capacity, removal efficiency and pressure drop, depend on the inlet air properties (contaminants, concentration and air flow rate), filter design options (packed bed or micro-fibrous material) and filter footprint (area, thickness and weight) [6].

In the present work, simulation for chemical adsorption behavior of air filter has been studied, which is based on Fluent. We simulated the adsorption of $\mathrm{SO}_{2}$ in the air filter. Not only the distribution of $\mathrm{SO}_{2}$ capacity with time in filter could be shown, but also the durability of filter can be evaluated. Furthermore, the velocity of flow and pressure drop of filter also be simulated. The simulation study for chemical adsorption and hydrodynamics in fuel cell cathode air 
filter help to optimize air filter to be durable and effective.

\section{Methodes}

In this paper, granular activated carbon (GAC), modified by $\mathrm{KOH}$, has been used as adsorptive material to filtrate the air contaminations. AC was first put in a furnace under helium atmosphere at $800{ }^{\circ} \mathrm{C}$ for $1 \mathrm{~h}$ to remove possibly contained volatiles, and then impregnated into $\mathrm{KOH}$ solutions at $0.5 \mathrm{M} / \mathrm{L} \mathrm{KOH}$ concentration with stirring for $3 \mathrm{~h}$ at $45^{\circ} \mathrm{C}$, followed by dehydration in a vacuum oven at $100^{\circ} \mathrm{C}$ for $8 \mathrm{~h}$. Finally, ten adsorbent samples including the original AC sample were prepared and kept in a desiccator.

The prepared adsorbent was filled in the bed reactor and the adsorption behavior has been tested in the home-made test-bench. The Schematic diagram of experimental set-up was showed in Figure 1.

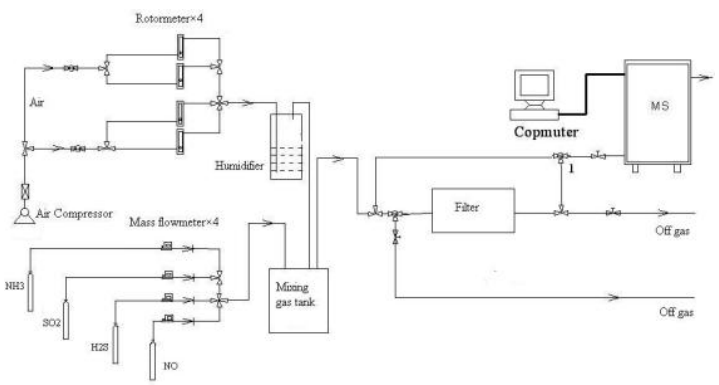

Figure 1. Schematic diagram of experimental set-up

According to the 3D mathematic model, CFD software Fluent has been applied in the air filter structure optimized design. The porous medium model and chemical adsorptive model based on UDF was set and chemical property of air filter element has been calculated in this paper.

\section{Results and Discussion}

\subsection{Effects of inlet Properties on adsorption}

The air flow rate of fuel cell vehicle depends on the system power; while the initial concentration of contaminations relies on atmosphere quality. These parameters are pivotal on the filter. So the effects of inlet properties on filter adsorption have been tested, the results have showed in Table.1. The results indicated that the breakthrough time decreased with the increase of initial concentration in the same airflow rate, and the breakthrough time also decreased with the increase of air flow rate in the same initial concentration.

Table 1 Effects of inlet Properties on adsorption

\begin{tabular}{|ccc|}
\hline $\begin{array}{c}\text { Initial } \\
\begin{array}{c}\text { Concentration } \\
(\mathrm{ppm})\end{array}\end{array}$ & $\begin{array}{c}\text { Air flow rate } \\
(\mathrm{m} / \mathrm{s})\end{array}$ & $\begin{array}{c}\text { Breakthrough } \\
\text { time }(\mathrm{min})\end{array}$ \\
\hline 13.2 & 0.088 & 380 \\
20.1 & & 248 \\
\hline
\end{tabular}

\begin{tabular}{|ccc|}
\hline 38.8 & & 152 \\
62.0 & & 78 \\
\hline 6.0 & & 244 \\
13.1 & 0.175 & 148 \\
22.5 & 98 \\
34.5 & & 70 \\
48.8 & & 49 \\
\hline 6.2 & & 140 \\
22.0 & 0.350 & 47 \\
31.5 & & 37 \\
40.0 & & 25 \\
\hline 2.3 & & 104 \\
4.2 & 0.701 & 50 \\
8.0 & & 23 \\
20.0 & & 15 \\
40.5 & & 14 \\
\hline
\end{tabular}

\subsection{Mathematic Model}

The adsorption mathematic model was founded based on the experimental data. The Wheeler formula (1) has been introduced to found the adsorption model. Wheeler formula is showed as flow:

$t_{b}=\frac{q \rho_{b}}{C_{0} Q}\left(H-\frac{Q}{k_{v}} \ln \left(\frac{C_{0}}{C_{x}}\right)\right)$

$t_{b}$ is breakthrough time, $q$ is equivalent adsorption weight, $\rho_{\mathrm{b}}$ is density of $\mathrm{GAC} \mathrm{C}_{0}$ is initial concentration, $\mathrm{Q}$ is air flow rate, $\mathrm{H}$ is bed ply, $\mathrm{k}_{\mathrm{v}}$ is adsorption speed constant, $\mathrm{C}_{\mathrm{x}}$ outlet concentration for breakthrough. Figure 2 showed the Wheeler Equation fits according to the experimental data.

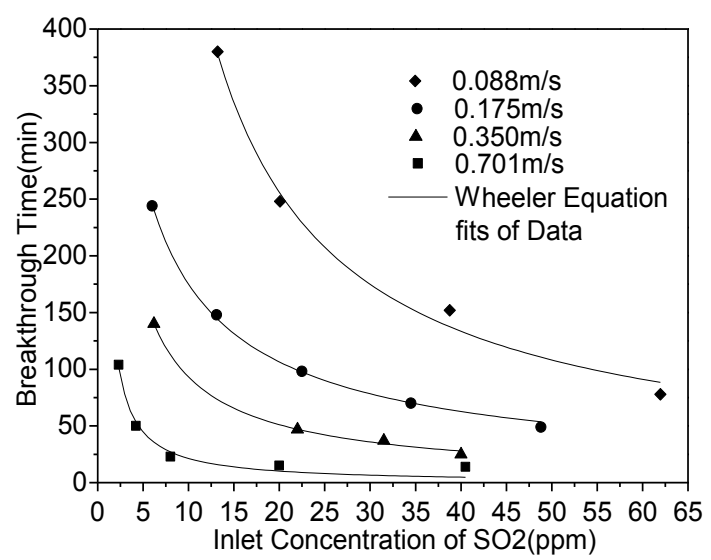

Figure 2 effects of breakthrough time on initial concentration at different flow rate

The Datafit software was used in the paper and the 3D mathematic model has been founded, which was showed in figure 3 . The breakthrough time can be calculated on the certain inlet concentration and flow rate according to this $3 \mathrm{D}$ model, which is in the area of initial concentration and airflow rate. 


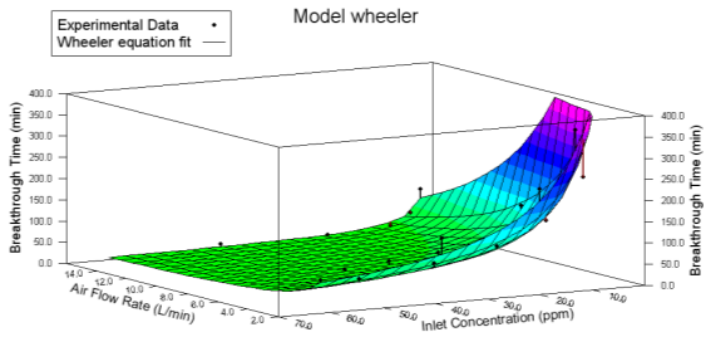

Figure 3 3D model for breakthrough time-inlet concentrationflow rate

Figure 4 showed the simulated result and experiment data and the hollow symbol is simulated result and the other is experiment data, which showed the simulation accorded with the experiments.

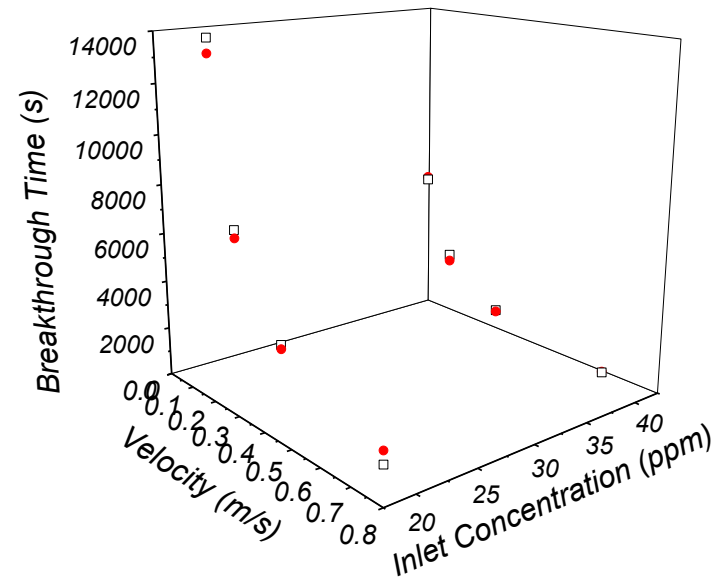

Figure 4 Comparison between simulation and experiment data for GAC adsorption.

\subsection{Simulation for Air Filter}

According to the 3D mathematic model, CFD software Fluent has been applied in the air filter structure optimized design for a $5 \mathrm{~kW}$ fuel cell stack system. The porous medium model and chemical adsorptive model based on UDF was set and the hydrodynamic and chemical property of air filter has been calculated in this paper. Figure 5 showed the distribution of velocity of flow in filter, the result showed that the distribution of velocity is uniformity, the range is about $0.14 \mathrm{~m} / \mathrm{s}$ $0.29 \mathrm{~m} / \mathrm{s}$ well-proportioned distributed in the filter and only the maximal air velocity in the air filter reached about $14 \mathrm{~m} / \mathrm{s}$ in export. Figure 6 showed the distribution of pressure drop in filter. About 3719Pa of the pressure loss was obtained, which is in the acceptable range for pressure drop in filter.

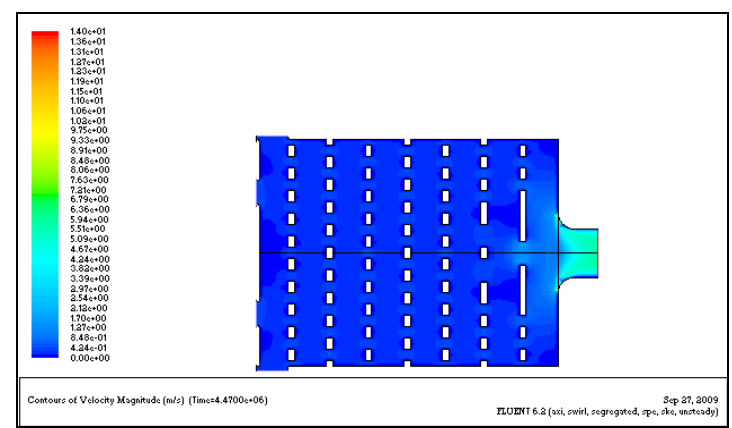

Figure.5 Distribution of velocity of flow in air filter

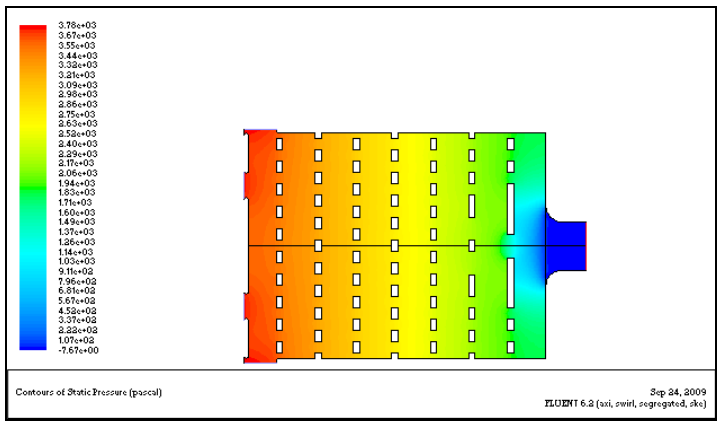

Figure.6 Distribution of pressure drop in air filter

Figure 7 showed the distribution of $\mathrm{SO}_{2}$ capacity with time in air filter. The SO2 adsorption in filter reached the saturation with time. Furthermore, the saturation capacity of $\mathrm{SO}_{2}$ is distributed uniformly in the filter, which attributed to particular design for the air filter. The life time of filter is about 1203 hours which can protect the fuel cell well. So the simulation study for chemical adsorption and hydrodynamics in fuel cell cathode air filter help to optimize air filter to be durable and effective.

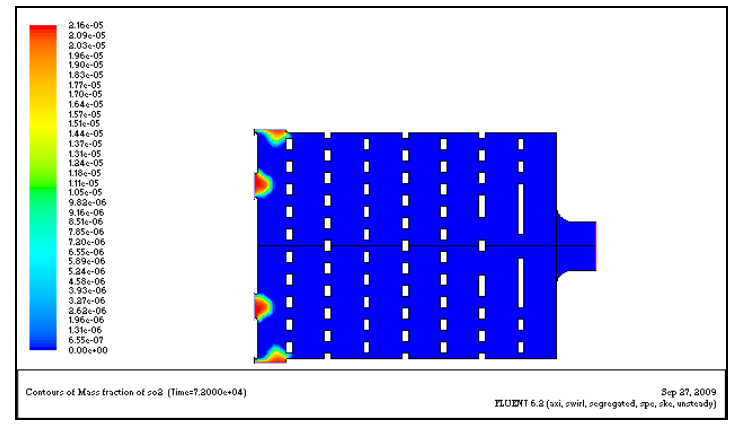

(a) 20 hours

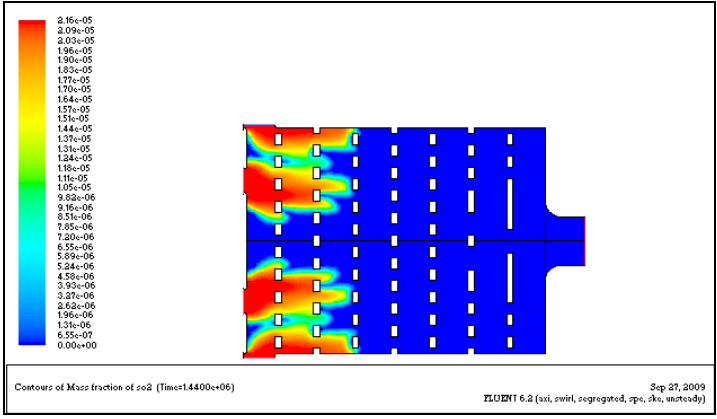

(b) 400 hours 


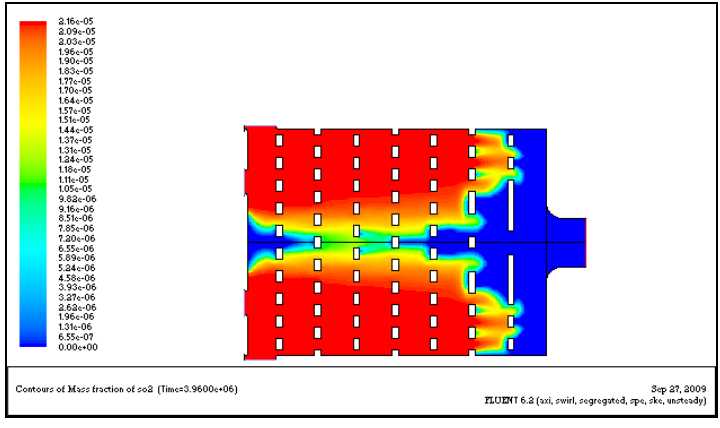

(c) 1100 hours

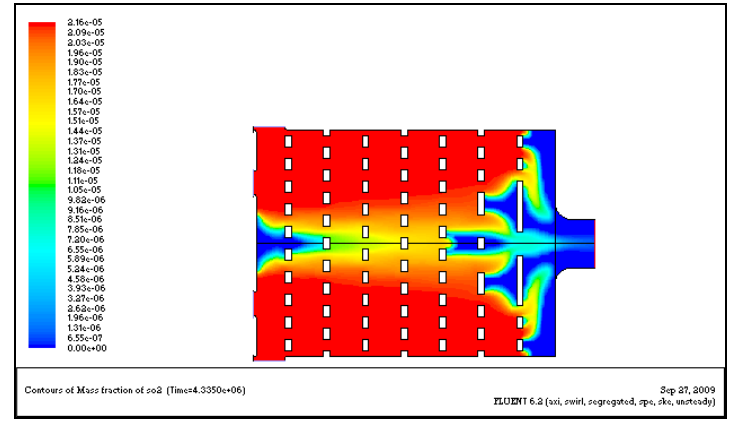

(d) 1200 hours

Figure 7 Distribution of SO2 capacity with time in air filter

\section{Conclusion}

The design and simulation for fuel cell cathode air filter has been studied in this paper. A three-dimension mathematic model between inlet property and adsorption property was built based on the GAC adsorptive experiment data. The breakthrough time can be calculated continuously and correspondingly in the area of initial concentration and airflow rate. According to the 3D mathematic model, CFD software Fluent has been applied in the air filter structure optimized design for a $5 \mathrm{~kW}$ fuel cell stack system. About $3719 \mathrm{~Pa}$ of the pressure loss was obtained and the life time of filter element is about 1203 hours. This air filter realized the design goal and can protect the fuel cell well.

\section{Acknowledgements}

We are grateful for the financial support of RFDP (serial number: 20090072120026) ,Training Program Foundation for the Youth Talents by Tongji University (serial number: 2009KJ082) and the Opening Foundation of Zhejing Provincial Top Key Discipline (20110923).

\section{References}

[1] D.J. Yang, J.X. Ma, L. Xu, M.Z. Wu, H.J. Wang, Electrochim. Acta 51 (2006) 4039-4044.

[2] F.N. Jing, M. Hou,W.Y. Shi, J. Fu, H.M. Yu, P.W. Ming,
B.L. Yi, J. Power Sources 166 (2007) 172-176.

[3] R. Mohtadi, W.K. Lee, J.W.V. Zee, J. Power Sources 138 (2004) 216-225.

[4] M.C. B’etournay, G. Bonnell, E. Edwardson, D. Paktunc, A. Kaufman, A.T. Lomma, J. Power Sources 134 (2004) 8087.

[5] J.M. Moore, P.L. Adcock, J.B. Lakeman, G.O. Mepsted, J. Power Sources 85 (2000) 254-260.

[6] D.M. Kennedy, D.R. Cahela, W.H. Zhu, K.C. Westrom, R.M. Nelms, B.J. Tatarchuk, J. Power Sources 168 (2007) 391-399.

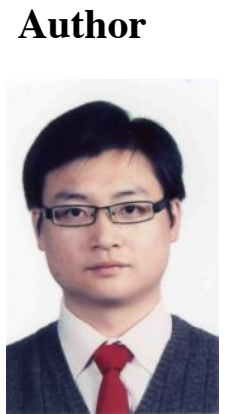

\section{Hong Lv}

Graduated from Shanghai Jiaotong University and obtained a PH.D degree. Now, the research field focuses on hydrogen and fuel cell technology. 